\title{
Некоторые вопросы безопасности применения
} дронов

\author{
Шакир Мехтиев ${ }^{1}$, Аяз Мехдиев ${ }^{2}$ \\ ${ }^{1,2}$ Институт Информационньх Технологий НАНА, Баку, Азербайджан \\ ${ }^{1}$ shakirliit.science.az, ${ }^{2}$ ayaz mehdiyevabk.ru
}

\begin{abstract}
Аннотация- Развитие информационно-коммуникационных технологий и микроминиатюризация электронной элементной базы обусловили прогресс в области производства и применений беспилотных летательных аппаратов. Данная статья посвящена исследованию некоторых вопросов безопасности, конфиденциальности и неприкосновенности частной жизни, которые являются объектами угроз при использовании гражданских беспилотных летательных аппаратов (дронов).
\end{abstract}

Ключевые слова- дрон, информационная безопасность, конфиденциальность, частная жизнь, угрозы, безопасность дронов

\section{I. ВВЕДЕНИЕ}

Происходившие на протяжении новейшей истории промышленные революции обусловили стремительный научно-технический прогресс во всех областях человеческой деятельности и, в частности, в области разработки и применения летательных аппаратов. Рассматриваемые в данной статье дистанционно управляемые беспилотные летательные аппараты (БПЛА), существенно уменьшившись в размерах, оснащенные современными микроэлектронными устройствами управления, навигации, видеонаблюдения и миниатюрными электрическими двигателями превратились из хобби в устройства массового использования для хозяйственных и иных нужд человека.

Первые сведения о применении БПЛА относят к 1849 г., когда с помощью неуправляемых воздушных шаров осуществлялась бомбардировка осажденной Венеции. Уже в 1898 г. Н. Тесла продемонстрировал возможности дистанционно радиоуправляемого судна, который послужил прототипом будущих разработок. В дальнейшем БПЛА использовались в военных и экспериментальных целях - боевые мишени, тактическая разведка, доставка боевого оружия, управление военными действиями и пр. Однако, подлинная история БПЛА, как дрона, берет начало в 1971 г., когда физик-ядерщик Джон С. Фостермладший (John S. Foster Jr.) в разведывательных целях оснастил небольшую авиамодель фотоаппаратом и сделал съемки местности с небольшой высоты. В будущем эта идея была использована и в гражданских применениях дронов.
В настоящее время повсеместное использование дронов породило множество проблем, начиная с безопасного осуществления полетов, юридических норм использования в общественных местах, неприкосновенности частной и семейной жизни, террористических угроз и пр. При отсутствии регулирующих норм и правил дроны могут быть легко использованы в незаконных целях, таких как наблюдение и несанкционированное слежение.

Целью данной работы является краткий анализ некоторых применений дронов и угроз, которые могут возникнуть от их использования.

\section{II. ОБЛАСТИ ПРИМЕНЕНИЯ ДРОНОВ}

Области применения дронов весьма разнообразны. Рассмотрим некоторые из них.

\section{A. Медицина}

Организация Definetz предложила использовать дроны для экстренной доставки дефибрилляторов и других средств в тех случаях, когда невозможно дождаться прибытия бригады медицинской помощи. Так, например, в случае приступа инфаркта миокарда или остановки сердца счет идет на минуты, и вовремя оказанная доврачебная помощь сохранит жизнь больному. В медицинской сфере дроны могут быть использованы для доставки товаров медицинского назначения в труднодоступные сельские районы [1, 2].

\section{Б. Видеосъемка}

В кинематографии видеосъемка с высоты птичьего полета создает новые ракурсы и возможности импровизации в творчестве, которые раньше не были возможны [3]. Дроны уже используются для подготовки репортажей с места событий и в спортивных соревнованиях. Еще одна область их применения создание документальных фильмов о дикой природе [4].

\section{B. Сельское хозяйство}

В сельском хозяйстве с помощью дронов собирается информация о состоянии посевных площадей, оценивается степень зрелости растений, необходимость поливов и проводится точечная обработка очагов заболеваний [5]. Оперативное обнаружение заболеваний растений 


\section{“Informasiya tohlükosizliyinin aktual multidissiplinar elmi-praktiki problemlori” IV respublika konfransı, 14 dekabr 2018-ci il}

позволяет принимать более точное решение по их лечению и мониторингу ситуации.

\section{Г. Нефтегазовая отрасль}

Стандартные подходы к мониторингу нефте- и газопроводов дополняются наблюдением с дронов. Сигналы с датчиков наблюдения и обнаружения утечек используются для идентификации текущего состояния трубопроводов и оценки экологической обстановки [6]. Качественные изображения в режиме реального времени позволяют оперативно обнаруживать нефтяные разливы и выявлять несанкционированную деятельность в охраняемых зонах.

\section{Д. Чрезвычайные происшествия}

Дроны используются в спасательных работах экстренными службами для поиска заблудившихся людей там, где доступ без спецсредств ограничен, например, в горной местности [7]. Дроны также оперативно могут доставить спасательные средства, еду и воду к месту катастроф, пожаров или землетрясений.

\section{E. Экологический мониторинг и гражданская наука}

Дроны применяют для изучения таяния полярных льдов, с их помощью определяют пути миграции животных, обнаруживают несанкционированные свалки, борются с браконьерами, выявляют случаи нарушения норм экологического законодательства, определяют уровень загрязнения, а также влияние различных загрязнителей на глобальную экологическую ситуацию [8, 9]. Данные с датчиков, рассеянных на земном ландшафте, передаются в сеть дронов для обработки. Весьма перспективной в этом направлении является концепция гражданской науки, под которой понимается проведение научных исследований с привлечением широкого круга добровольцев (гражданин-ученый). Предлагается использовать сети дронов граждан-ученых для комплексных наблюдений в различных географических районах [10]. Важной составляющей в сети дронов являются координация их действий и трансляция изображений в единый центр мониторинга, что необходимо для эффективности наблюдений и обеспечения точности исследований в случаях единичных отказов дронов.

Применение дронов не ограничивается приведенными примерами. Можно также отметить археологию, строительство, журналистику, геодезию, вулканологию и пр.

Этот краткий обзор позволяет сделать вывод о том, что использование дронов является весьма необходимым и актуальным направлением.

\section{III. ПОДХОДЫ К БЕЗОПАСНОСТИ ДРОНОВ}

Количество действующих дронов продолжает неуклонно расти. Можно безошибочно предсказать, что по мере увеличения их числа появится больше угроз информационной и физической безопасности, а также угроз конфиденциальности и вторжений в частную жизнь. Для эффективного обеспечения безопасности дронов необходим комплексный подход к решению следующих задач [11]:

- проектирование безопасности;

- мониторинг безопасности;

- у управление безопасностью.

Структурная схема гипотетического дрона представлена на рис. 1.

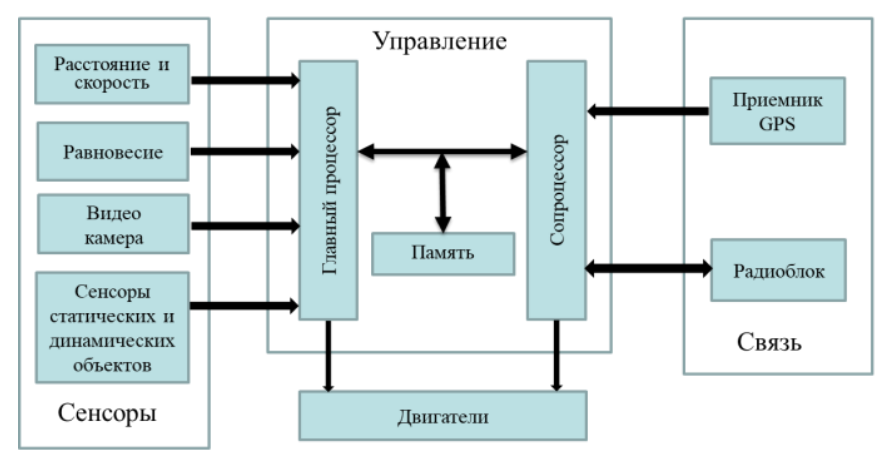

Рис. 1. Структурная схема дрона

Как следует из рис. 1, дроны могут управляться либо дистанционно, либо автономно с использованием бортовых компьютеров. Фактически дрон представляет собой модель киберфизической системы. Физические элементы на борту дрона используют сеть датчиков и исполнительных механизмов, которые взаимодействуют с наземной системой управления по беспроводной линии связи. Соответственно, система дрона уязвима для атак, нацеленных на киберфизические элементы, интерфейс между ними, беспроводную связь или даже комбинацию нескольких компонентов. Характерные угрозы информационной безопасности для дронов приведены на рис. 2.

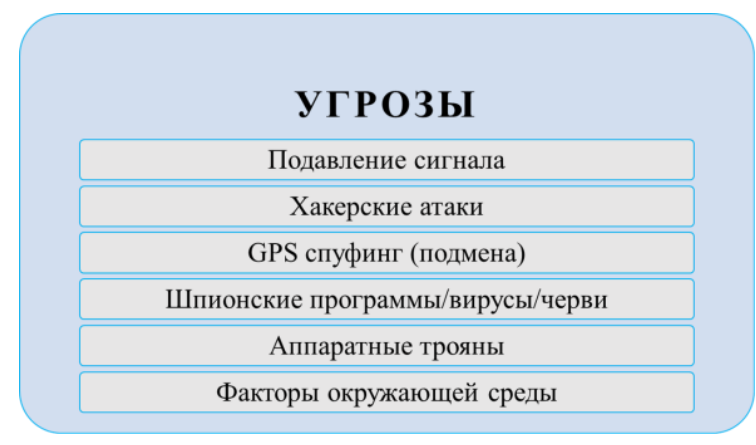

Рис. 2. Виды угроз информационной безопасности дронов

Указанные виды угроз достаточно подробно рассмотрены различными авторами. Отметим, что спуфинг (spoofing attack) - это метод передачи дрону ложных навигационных данных для перехвата его управления [12]. В последнее время также появились публикации, в которых приводятся сведения о технологических возможностях внедрения аппаратных троянов 


\section{“Informasiya tohlükosizliyinin aktual multidissiplinar elmi-praktiki problemlori” IV respublika konfransı, 14 dekabr 2018-ci il}

непосредственно на стадии изготовления микрочипов [13, 14]. Факторы окружающей среды (погодные условия, птицы и пр.) могут привести к прекращению функционирования дронов: функциональный отказ или невозможность проведения видеонаблюдения.

Важной проблемой использования дронов является их интеграция в национальное воздушное пространство с одновременным обеспечением высокого уровня физической безопасности. Трудно представить ситуацию, когда, выполняя миссию по доставке грузов или осуществляя журналистскую деятельность, дрон из-за возникшей неисправности упадет на места скопления людей, замкнет линии электропередач или же создаст помехи в пределах аэропортов и других важных государственных учреждений. К сожалению, подобное случается. Использование дронов ставит задачу контроля за воздушным пространством и его разделения с пилотируемыми летательными аппаратами (самолетами и вертолетами). Производители дронов внедряют в их программное обеспечение блоки с геолокационными ограничениями в бесполетных зонах. Профилактической мерой в решении данной проблемы служат различные законодательные и нормативные акты. Однако, эти акты не являются международными стандартами и в различных странах правила использования дронов имеют различную интерпретацию. В Евросоюзе в 2015 г. была принята нормативно-правовая база в данном направлении [15]. Однако, в некоторых странах действуют локальные нормативы. Так, в Ирландии все дроны массой более 1кг должны быть зарегистрированы в Авиационном управлении (IAA). Кроме того, дрон не должен эксплуатироваться, если это будет представлять опасность для другого летательного аппарата в полете или подвергать опасности жизнь или имущество других лиц [16]. В Италии действует запрет на использование разновидности дронов - квадрокоптеров (для некоммерческой съемки, массой меньше 25 кг) при большом скоплении людей, в городах, рядом с железнодорожными вокзалами, аэропортами, военными объектами, электростанциями и правительственными учреждениями. Другие подобные регулирующие акты существуют в США, Великобритании, Японии, России и пр. [17]. В Азербайджанской Республике применения дронов регулируются “Законом об Авиации” и "Правилами использования воздушного пространства Азербайджана" [18, 19].

Широкое распространение дронов создало угрозы для вторжений и в частную жизнь граждан. Следует отметить, что международными документами право граждан на неприкосновенность частной жизни признано фундаментальным понятием. Во Всеобщей декларации прав человека зафиксировано, что "никто не может подвергаться произвольному вмешательству в его личную и семейную жизнь, произвольным посягательствам на неприкосновенность его жилища, тайну его корреспонденции или на его честь и репутацию” [20]. В Конституции Азербайджанской Республики также гарантировано право гражданина на личную неприкосновенность. Без согласия гражданина сбор, хранение, использование и распространение сведений о его частной и семейной жизни, видео- и фотоматериалов не допускаются [21].

Дроны, оснащенные средствами аудио- и видеозаписи, могут быть использованы в незаконных целях, начиная от наблюдения до несанкционированного слежения. Для предупреждения подобных случаев предусмотрены правовые барьеры в законодательствах различных стран, в том числе и в Азербайджане [22].

Дроны собирают информацию одним из двух способов: записи хранятся на борту (например, на карте памяти или жестком диске) либо передаются обратно на центральное устройство, где они затем сохраняются. Оба метода имеют уязвимости. Если дрон с бортовым хранилищем будет потерян или захвачен несанкционированным третьим лицом, то же самое будет и с информацией, которую он несет. Если дрон передает информацию через беспроводное соединение, это соединение можно перехватить и использовать для доступа или изменения информации при передаче. Для устранения этих уязвимостей следует использовать адекватные меры защиты, такие как защита паролем и шифрование.

При использовании дронов угрозы конфиденциальности могут произойти по следующим причинам [23]:

- $\quad$ информация, собранная для одной цели, затем из корыстных побуждений передается третьей стороне;

- люди не осознают, что они находятся под наблюдением и не понимают, для чего будет использоваться информация;

- навязчивая практика наблюдения в достижении поставленной задачи;

- в процессе наблюдения собирается больше информации, чем это необходимо.

В некоторых случаях допускается разумное использование или раскрытие информации. Это может произойти по следующим причинам:

- уменьшение или предотвращение серьезного риска для отдельного лица или для общественности;

- использование или раскрытие информации разрешено по закону;

- использование или раскрытие информации необходимо для правоохранительной деятельности.

\section{IV. ЗАКЛЮЧЕНИЕ}

Использование гражданских дронов частными лицами и их применения весьма разнообразны и имеют тенденцию к расширению. Развитие дронов идет в направлении обеспечения безопасности воздушного движения. Однако обеспечение информационной безопасности дронов также становится весьма актуальной проблемой в контексте 


\section{“Informasiya tohlükosizliyinin aktual multidissiplinar elmi-praktiki problemlori” IV respublika konfransı, 14 dekabr 2018-ci il}

противодействия угрозам угонов дронов и их противоправного применения криминальными и террористическими группировками. Законодатели и административные органы должны предвидеть потенциальные проблемы, которые могут привести к бесконтрольному использованию и злоупотреблению дронов.

\section{ЛИТЕРАТУРА}

[1] Ш. Мехтиев, Б. Агаев, “Медицинская электроника: состояние, проблемы и перспективы," Elektron tibbin multidissiplinar problemləri, Bakı, 2016, ss.110-113.

[2] I. Subbarao, G. P. Cooper, "Drone-based telemedicine: a brave but necessary new world," The Journal of the American Osteopathic Association, 2015, Vol 115,| No. 12, pp. 700-701.

[3] A. Rango, et al, "Using unmanned aerial vehicles for rangelands: current applications and future potentials," Environmental Practice, 2006, Vol.8, No.3, pp.159-168.

[4] K. Collins "Behind the mind-boggling shots captured by BBC drones," 2014. https://www.wired.co.uk/article/bbc-drone-journalism

[5] P. Tripicchio, et al, "Towards smart farming and sustainable agriculture with drones," International Conference on Intelligent Environments, Prague, 2015, pp. 140-143.

[6] T. Kh. Fataliyev, Sh. A. Mehdiyev, "Analysis and new approaches to the solution of problems of operation of oil and gas complex as a cyberphysical system," International Journal of Information Technology and Computer Science (IJITCS), 2018, Vol.10, No.11, pp.67-76.

[7] S. Waharte, N. Trigoni, "Supporting search and rescue operations with UAVs," International Conference on Emerging Security Technologies, 2010, pp.142-147.

[8] A. Philips, "A glimpse into how eco-drones are changing environmental research for the better," 2015. https://projectearth.us/a-glimpse-intohow-eco-drones-are-changing-environmenta-1796519323

[9] B. Ivošević, et al, "The use of conservation drones in ecology and wildlife research," Ecology and Environment, 2015, Vol.38, No.1, pp.113-188.

[10] T. X. Fətəliyev, "Vətəndas elmi e-elmin inkişafinın yeni istiqaməti kimi," İnformasiya Cəmiyyəti Problemləri, 2014, № 1, ss. 57-64.

[11] R. M. Alguliyev, R. G. Alakbarov, T. Kh. Fataliyev, "Electronic science: current status, problems, and perspectives,", Problems of information technology, 2015, №2, pp. 4-14.

[12] S. M. Giray, "Anatomy of unmanned aerial vehicle hijacking with signal spoofing," 6th International Conference on Recent Advances in Space Technologies (RAST), 2013, pp.795-800.
[13] J. Villasenor, "The Hacker in Your Hardware," Scientific American, 2010, Vol. 303, No. 2, pp. 82-87.

[14] Ş. Mehdiyev, Y. İmamverdiyev, "E-dövlətin informasiya təhlükəsizliyi və texnoloji çağırışlar,” Informasiya təhlükəsizliyinin multidissiplinar problemləri, Bak1, 2015, ss. 130-133.

[15] "Introduction of a regulatory framework for the operation of drones, European Aviation Safety Agency," A-NPA 2015-10, p.41. https://www.easa.europa.eu/sites/default/files/dfu/A-NPA\%20201510.pdf

[16] "Regulating Drones: Safety, Security, and Privacy," 2016 https://www.mhc.ie/latest/blog/regulating-drones-safety-security-andprivacy

[17] “Master List of Drone Laws.” https://uavcoach.com/drone-laws/

[18] "Aviasiya haqqında Azərbaycan Respublikasının Qanunu”, 2005, http://www.caa.gov.az/index.php?option=com_k2\&view=item\&id=94:la w-of-the-republic-of-azerbaijan-on-aviation\&Itemid=173\&lang=az

[19] “Azərbaycan Respublikasının hava məkanından istifadə Qaydaları” 2013 http://www.e-qanun.az/framework/33800

[20] "Universal declaration of human rights," 217(III) International Bill of Human Rights, 1948.

[21] “Azərbaycan Respublikasının Konstitusiyası,” 26 sentyabr 2016 www.president.az

[22] "Azərbaycan Respublikasinin Cinayət Məcəlləsi." http://www.eqanun.az/code/11

[23] "Drones and the Privacy Principles," Office of the Information Commissioner Queensland, 2018. https://www.oic.qld.gov.au

\section{SOME SECURITY ISSUES OF USING DRONES}

Shakir Mehdiyev ${ }^{1}$, Ayaz Mehdiyev ${ }^{2}$

sshakir@iit.science.az, ${ }^{2}$ ayaz_mehdiyev@bk.ru

Institute of Information Technology of ANAS, Baku, Azerbaijan

Abstract -- The development of information and communication technologies and microminiaturization of electronic components have also led to progress in the production and applications of unmanned aerial vehicles. This article is devoted to the study of some issues of security, confidentiality, and privacy, which are the objects of threats when using of civilian unmanned aerial vehicles (drones).

Keywords - drone, information security, confidentiality, privacy, threats, security of drones 